\title{
A redescription of \\ Trypanosoma cotti Brumpt and Lebailly, 1904 and its development in the leech, Calliobdella punctata
}

\author{
par R. A. KHAN \\ Department of biology and Marine Sciences Research Laboratory \\ Memorial University of Newfoundland St. John's, Nfld. Canda A1C 5S7
}

Summary.

Trypanosoma cotti Brumpt and Lebailly, 1904 is redescribed from Brumpt's blood slides prepared from the sea scorpion (Enophrys bubalis). Developmental stages occur in the intestine of the marine leech Calliobdella punctata, which acts as the vector. Division occurs only in the amastigote stage which subsequently changes into a sphaeromastigote and epimastigote forms. Yellow pigment granules characterize all developmental stages except slender epimastigotes. No metatrypanosomes were observed.

\section{Résumé.}

Redescription de Trypanosoma cotti Brumpt et Lebailly, 1904 et son développement chez la sangsue marine Calliobdella punctata.

Trypanosoma cotti Brumpt et Lebailly, 1904 est redécrit à partir des frottis de sang du Scorpion de mer (Enophrys bubalis) faits par E. Brumpt. Des stades évolutifs se développent dans l'intestin de la Sangsue marine Calliobdella punctata, qui transmet le parasite. La division ne s'effectue qu'au stade amastigote, qui évolue par la suite et devient sphaéromastigote et épimastigote. Des granules de pigment jaune caractéristiques se trouvent dans tous les stades évolutifs, sauf dans les épismastigotes fins. Aucun métatrypanosome n'a été observé.

Accepté le 15 avril 1978. 


\section{Introduction}

Following his thesis on reproduction of leeches, Brumpt (1904) investigated their role as vectors of piscine hematozoa. Simulateneously, in association with Lebailly, he described several new species of blood parasites of fish. Included among them was Trypanosoma cotti which was characterized: total length $53 \mu \mathrm{m}$; body length $45 \mu \mathrm{m}$ and $8 \mu \mathrm{m}$ for free flagellum; body width $8 \mu \mathrm{m}$; kinetoplast $7 \mu \mathrm{m}$ from the posterior end; nucleus equidistant from the kinetoplast and the flagellum base. The host is the sea scorpion [Enophrys $(=$ Cottus) bubalis-vide Sandercock and Wilimovsky, 1968]; three of four were infected (Brumpt and Lebailly, 1904). The authors called attention to the similarity of larger specimens to those of $T$. gobii from which it did not differ morphologically or morphometrically. A year later, in a review of the trypanosomes, Brumpt (1905) illustrated four developmental stages of $T$. cotti (his fig. 40) in an unspecified leech without referring to them in the text. Brumpt (1906 a) subsequently reported transmission of $T$. cotti by a marine leech, Calliobdella (= Callobdella) punctata to $E$. bubalis. Brief notes were made later (Brumpt, $1906 \mathrm{~b}, 1910$ ) of $T$. cotti which developed only in the stomach of $C$. punctata and never entered the proboscis sheath. Promastigote $(=$ leptomonas) and epimastigote (= crithidia) forms arose from a process of multiple division (Brumpt, 1910). Epimastigotes were reported to be heavily impregnated with black pigment granules.

The foregoing account of $T$. cotti by Brumpt appeared brief in contrast to his (1906 a) study of $T$. granulosum and to the later works of Robertson (1907, 1909 and 1912) and Neumann (1909) who both described in detail the morphology and development of trypanosomal stages in both piscine hosts and in leeches. Brumpt's material was left at the Laboratoire de Zoologie (Vers), Muséum National d'Histoire naturelle in Paris, France. It was recently made available for study. A close examination revealed that $T$. cotti was inadequately described, and likewise its development in the leech, $C$. punctata. A description of these stages follows.

\section{Materials and Methods}

Brumpt's material was prepared from animals taken in Atlantic waters, probably in 1902 and 1905 at Roscoff, Brittany, France. It had been stained with a Romanovsky stain and considering it was at least 70 years old, was in reasonably good condition.

\section{Descriptive Account}

BRUMPT AND Lebailly, 1904 (fig. 1 to 3).

Diagnosis (measurements in $\mu \mathrm{m} \pm$ to the standard deviation): Body long, slender to thick set, attenuated at both extremities $48.7 \pm 5.0$ by $3.6 \pm 0.6$; cytoplasm 
with few to no dark blue granules and no apparent myonemes in slender forms, but with many granules and 6 to 9 myonemes in thick-set ones; vacuoles more apparent in thick-set forms; nucleus ovoid, same as body width, almost equidistant between kinetoplast and anterior extremity; nucleus to posterior end $27.5 \pm 3.4$; kinetoplast ovoid, $7.9 \pm 1,7$ from posterior end; undulating membrane present; free flagellum $8.3 \pm 1.3$; distance from kinetoplast to nucleus $19.6 \pm 2.6$; distance from nucleus to anterior extremity $21.2 \pm 2.9$; nuclear index (nucleus to anterior end/ nucleus to posterior end) 1.2 ; kinetoplastic index (posterior end to nucleus/kinetoplast to nucleus) 1.4 .

Type Host: Enophrys (= Cottus) bubalis, the sea scorpion (Teleostei, Cottidae) Roscoff, France in North Atlantic Ocean. Type and paratypes at Laboratoire de Zoologie, Museum National d'Histoire naturelle.

Vector: Marine leech, Calliobdella (= Callobdella) punctata. Amastigotes (fig. 4 to 6) ovoid to oblong, sizes variable $11.7 \pm 1.9$ with nucleus 3 by 3 , kinetoplast and three to several yellow pigment granules; divisional stages with two mastigont organelles present; sphaeromastigotes (fig. 7 and 8) tadpole-like, $14.7 \pm 4.4$ with flagella of variable length, nuclei and several pigments granules; no evidence of division; epimastigotes (fig. 9-13) $29.6 \pm 9.3$ by $3.0 \pm 0.7$ long, slender, cytoplasm pale-staining, with none to several yellow pigment granules and with kinetoplast and free flagellum of variable length, no evidence of division; metatrypanosomes unknown.

\section{Comments}

Morphological and morphometrical data on trypomastigotes of $T$. cotti are based primarily on material from two slides (nos. 6 and 32) prepared from sea scorpions. The morphology and parasitemia on the slides were distinct; presumably they were derived from different fish. It should be recalled that Brumpt and Lebailly (1904) noted infections in three of four E. bubalis. In one of the preparations (no. 6) the morphs were slender with no visible evidence of myonemes whereas, in the other, which harboured many more parasites, most of them possessed myonemes and were granular.

From Brumpt's preparations, it appears that trypomastigotes proceeded to round up in the leech about five hours after their ingestion (fig. 4). Cytoplasmic granules were still evident and in some cases, quite pronounced. Profuse multiplication of the amastigotes occurred by 23 to 26 hours and numerous forms with two sets of mastigont organelles were observed (fig. 5).

Yellow pigment granules (Brumpt, 1910, referred to them as black pigment) were not apparent. The resulting progeny were evidently smaller (fig. 6). According to Brumpt (1905), the occurrence of these and subsequent stages were restricted to the intestine. There were also few sphaeromastigotes (fig. 7 and 8 ) and in one leech, numerous epimastigotes. The former appeared to be a transitory stage between amastigotes and epimastigotes and there was no evidence that they were dividing. 

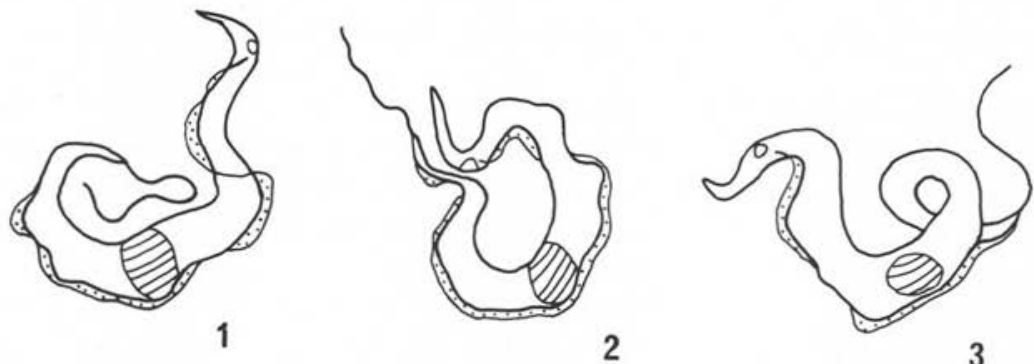

2

3
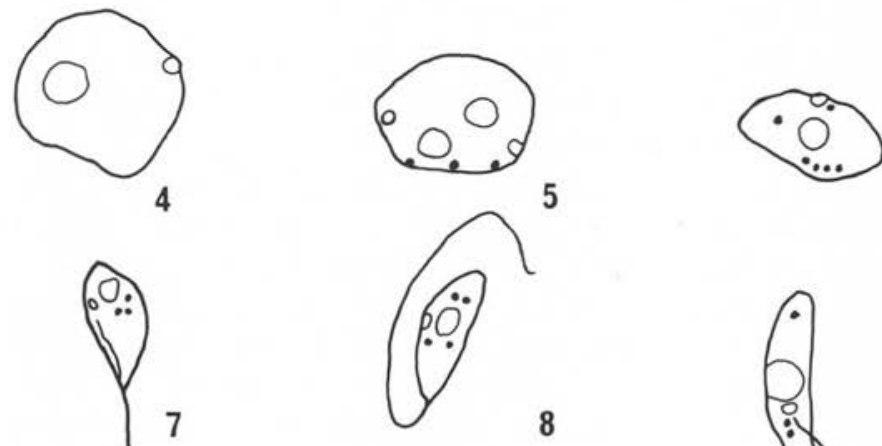

6

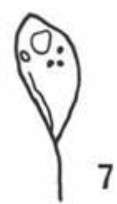

8
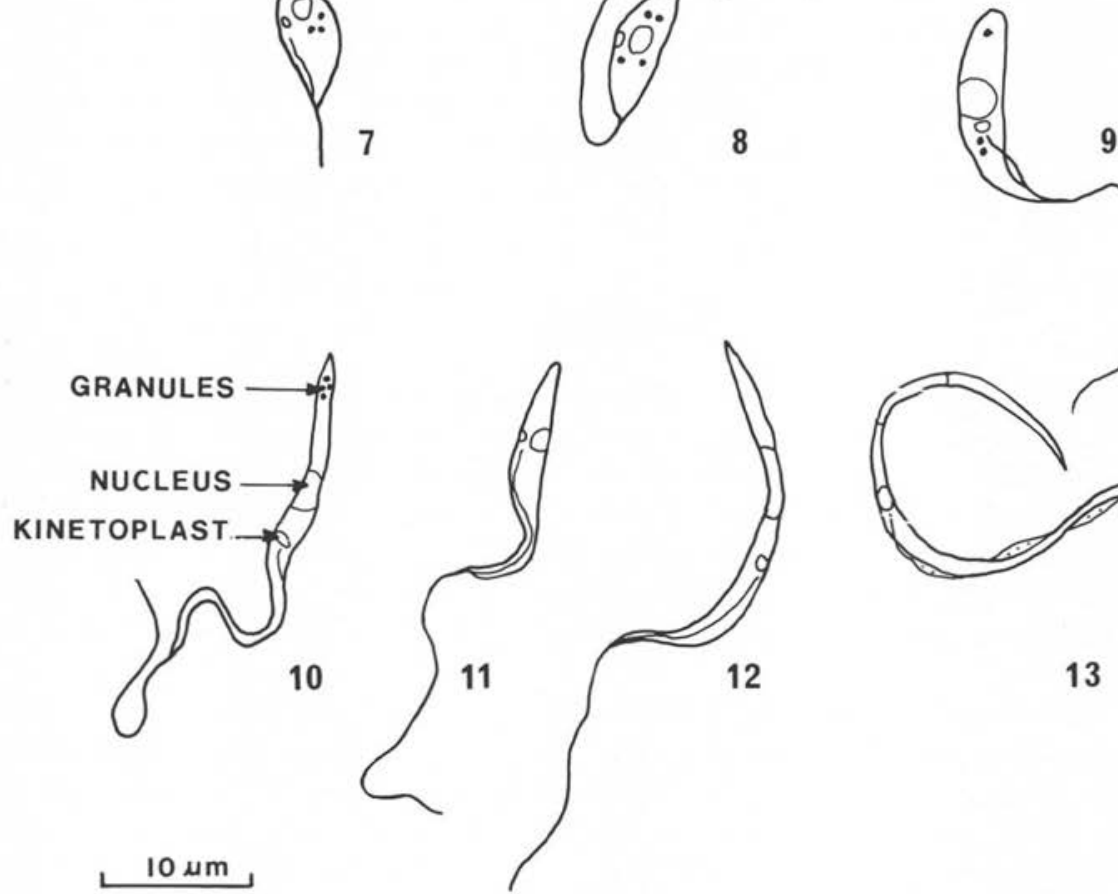

9

$10 \mu \mathrm{m}$

Fig. 1 à 13. Line illustrations of $T$. cotti and its developmental stages in the stomach of C. punctata.

Fig. 1-3. Trypomastigotes from the blood of E. bubalis.

Fig. 4-6. Amastigotes (dividing in fig. 5).

Fig. 7-8. Sphaeromastigotes.

Fig. 9-13. Epimastigotes. Note lack of pigment in epimastigotes, fig. 11-13.

Granules refer to yellow pigment granules. 
All stages harboured yellow pigment granules. Epimastigotes, ranging from short, thick forms with yellow pigment granules to others that were long and slender and devoid of pigment (fig. 9 to 13) were present. An undulating membrane was apparent in them. The flagella were long in the slender forms and their nuclei were elongate rather than ovoid (fig. 12 and 13). At later intervals after feeding (48 hours), only epimastigotes were observed; the slender forms were more abundant. Probably the small, thick forms grow into the large, slender morphs, which subsequently loose their yellow pigment granules. No epimastigotes were observed dividing nor were metatrypamosomes observed in any of the preparations. Although the nature of the infective stage was not specified by Brumpt, Wenyon (1926) stated that it was a metatrypomastigote $(=$ trypanosome form). Transmission of $T$. cotti was achieved by the bite of an infected $C$. punctata (Brumpt, 1906 a).

\section{Discussion}

Trypanosoma cotti was described during a period when host specificity of parasites was envisaged in its strictest sense. However, since this time, studies have shown that some piscine trypanosomes might not be host specific, as at least one species, T. murmanensis, will infect fish closely related to its host species, the Atlantic cod (Gadus, morhua), as well as taxonomically distant species (Khan, 1977). Moreover, morphological and morphometrical data of $T$. cotti does not render it significantly different from $T$. gobii, a fact pointed out by Brumpt and Lebailly (1904). Since the piscine hosts occupy the same ecological niche and are probably transmitted by the same leech, it is possible that they are identical. The same point can also be raised for species of trypanosomes described from Heterosomata, especially the European forms (Cottrell, 1977). However, experimental transmission, using laboratory reared leeches would be prerequisite to the elucidation of these questions.

The granules - described as black pigment by Brumpt (1910) - noted in developmental stages of $T$. cotti appeared yellow and were refractile to transmitted light. Similar granules have also been reported in developmental stages of another fish trypanosome (Khan, 1976) as well as in amphibian (Woo, $1969 \mathrm{~b}$ ) and chelonian trypanosomes (Woo, $1969 a$ ). The nature of these granules is at the present time enigmatic.

\section{Bibliography}

Brumpt E. (1905): Trypanosomes et trypanosomoses. Rev. Scient., Paris, 4, 330-332.

Brumpt E. $(1906 a)$ : Expériences relatives au mode de transmission des trypanosomes et des trypanoplasmes par les hirudinées. C. R. Soc. Biol. Paris, 61, 77-79.

Brumpt E. $(1906 \mathrm{~b})$ : Mode de transmission et évolution des trypanosomes des poissons. Description de quelques espèces de trypanoplasmes de poissons d'eau douce. Trypanosome d'un crapaud africain. C. R. Soc. Biol. Paris, 60, 162-164. 
Brumpt E. $(1906 c)$ : Sur quelques espèces nouvelles de trypanosomes parasites des poissons d'eau douce; leur mode d'évolution. C. R. Soc. Biol. Paris, 60, 160-162.

Brumpt E. (1910): Sur quelques particularités morphologiques et physiologiques des trypanosomes (perte du flagelle et formation de pigments divers). Bull. Soc. Pathol. Exot., 3, 366-367.

Brumpt E., Lebailly C. (1904) : Description de quelques nouvelles espèces de trypanosomes et de hémogrégarines parasites des téléostéens marins. C. R. Acad. Sci., Paris, 139, 613-615.

Cottrell B. J. (1977) : A trypanosome from plaice, Pleuronectes platessa L. J. Fish. Biol., 11, 35-47.

Khan R. A. (1976): The life cycle of Trypanosoma murmanensis Nikitin. Can. J. Zool., 54, 18401849.

Khan R. A. (1977): Susceptibility of marine fish to trypanosomes. Can. J. Zool., 55, 1235-1241.

Neumann R. O. (1909): Studien über protozoische Parasiten im Blute von Meeresfischen. Z. Hyg. Infektionskr., 64, 1-112.

Robertson M. (1907): Studies on a trypanosome found in the alimentary canal of Pontobdella muricata. Proc. R. Phys. Soc. Edinburgh., 17, 83-108.

Robertson M. (1909) : Further notes on a trypanosome found in the alimentary tract of Pontobdella muricata. Q. J. Microsc. Sci., 54, 119-139.

Robertson M. (1912) : Transmission of flagellates living in the blood of certain freshwater fishes. Phil. Trans. R. Soc. London, Ser. B, 202, 29-50.

Sandercock F.H., Wilimovsky N.J. (1968): Revision of the cottid genus Enophrys. Copeia, 30, 832-853.

Woo P. T. K. (1969a): The life cycle of Trypanosoma chrysemydis. Can. J. Zool., 47, 1139-1151.

Woo P.T.K. $(1969 \mathrm{~b})$ : The development of Trypanosoma canadensis of Rana pipiens in Placobdella sp. Can. J. Zool., 47, 1257-1259. 